\title{
Name and Reality, Physical Usages and Meaning: A Study on the Origin of Dan Culture ${ }^{1}$
}

\author{
Zhang Ying ${ }^{2}$ \\ The Institute of Anthropology, Xiamen university
}

\begin{abstract}
"Dan" is a Taoist method that integrates Chinese life culture. Between things and non-things, as the holy things that condense the essence of heaven and earth, Dan is not only the survival philosophy and life science passed down from generation to generation for thousands of years in China, but also the life aesthetics accompanied by the present reality. It creates, carries and reflects the thinking logic, perception mode and living habit of local traditional culture. It is the most important and rich "home heritage” of Chinese traditional culture. ${ }^{3}$
\end{abstract}

Keywords: Dan Traditional Culture Homeland Heritage

"Cinnabar (Dan Sha) is the Lord of all spirits, the root of creation and the origin of gods." ${ }^{4}$ Ancient Chinese believed that Dan is a condense with essence of heaven and earth, a symbol of the sun, fire and blood and soul. As carrier, it can realize the eternity of life through the transformation of Yin and Yang. Tracing back the history, no matter kings and nobles, scholars, monks and sorcerers, plebs and craftsmen, they all took part in the activities of seeking, collecting, refining, eating and explaining Dan. If "jade" is a material carrier throughout Chinese ritual and music culture, "Dan" is a Taoist method integrated with Chinese life culture. It contains the principles of heaven and earth, the matter of life and death, the virtue of the saints. In a broad sense, "Dan" is the precipitation of Chinese history, thoughts and beliefs.

\section{I . Name and Categories of Dan}

In the Shuowen·Dan Radical, Dan (丹) is explained as "red stone in Ba and Yue area. Like the well of Dan, the shape of Dan”. Oracle bone script is added with a explanatory notation $\mathbf{z}$ in mine well $\boldsymbol{H}$, which means there is Dan in the well. Bronze inscription $\mathbf{y}$, seal script $\mathbf{A}$ follows the oracle bone script. In official script，丹 is “丹” which is different from “舟 (boat)”. There are characters combining with丹, for example,

\footnotetext{
1 This paper is the phased achievement of 2011 national social science fund major project "exploration and research on China's intangible cultural heritage system" (approval number: 11\&ZD123). Funded by China postdoctoral science foundation, the periodical achievement of "seeking roots in natural history: applied anthropology research of Wanshan mercury mine in Guizhou". This article was funded by the program of Shanghai Jiao Tong University titled "World-class Universities and First-class Subjects", and the program of Shanghai City titled "Shanghai Social Science Research and Innovation Base: Chinese Creation Myth Studies" (2017WSH002).

2 About the author: Zhang Ying (1975-), female, a native of Chongqing, is postdoctoral student in the Institute of anthropology, Xiamen university. Research track: cultural heritage, museums, anthropology.

${ }^{3}$ See Peng Zhaorong: Home heritage: anthropological perspective of modern heritage science, Journal of Xuzhou Institute of Engineering, 2013, 5 (73-78). The concept of "home heritage” points out that any heritage has its own reason of existence, way of existence and category of existence, emphasizing the historical generation logic and expression form of cultural heritage itself. The proposal of this concept not only profoundly reflects the divergence between the power of heritage and the owner of heritage, but also provides a strategy for heritage protection and inheritance in the context of globalization.

${ }^{4}$ Taoist collection, vol. 19, Cultural relics press, Shanghai bookshop, Tianjin ancient books press, 1988, p. 15.
} 
姗 (tong, red), 砃 (dan, white stone), 玬 (dan), 斿 (zhan, red flag), 蚒 (tong, red), 臒 (huo, beautiful color), 鵃 (huan, a creature having a human face and a bird's beak), etc.; words with 丹 (dan) like 丹青 (danqing, paintings), 丹霞 (danxia, sunset clouds), 丹文 (danwen, red pattern), 丹诏 (danzhao, imperial edict written in red by emperors), 丹术 (danshu, techniques of alchemy ), 丹诀 (danjue, methods of alchemy), 丹方 (danfang, methods of alchemy), 丹药 (danyao,elixir), 丹田 (dantian,elixir field), 丹府 (danfu, sincere heart), 丹心 (danxin, loyal heart), 丹念 (dannian,), etc.; There are numerous idioms related to 丹 (dan), such as 丹青不渝 (unswerving), 碧血丹心 (loyal-hearted), 铁券丹书 (privilege certificate given to ministers from emperors), 妙手丹青 (skillful painters), 灵丹妙药 (cure-all medicine), 枫丹白露 (poetic landscape), 丹楹刻桷 (the finest architecture), 浮翠流丹 (colorful), 丹漆随梦 (follow the ancient sages), and 璇霄丹阙 (wonderland). Most of the above three categories refer to goodness, holiness and sincerity.

The character "Dan" can be found everywhere in the collection of ancient Chinese classics and historical records. It first appeared in the Book of History. In Yi Ji: "Compensate them with horses and chariots. In this way, who dare not step down for other of ability? who dare not respectfully accept your orders? The emperor is not good to distinguish good and bad, although every day he uses people, he will also work in vain. There was nothing so arrogant as Danzhu, nothing but idleness, nothing but banter, no matter day or night. Now that the flood waters had receded, he would travel by boat and play in groups at home. Here "Dan zhu", is the eldest son of Yao, the chief of the ancient Chinese tribal alliance. Legend has it that he was born red and bright as a child. But because he wasn't "like his father", he was eventually exiled in Danshui, Yao gave the position of tribal alliance leader to Shun. Dan recorded in Yu Gong refers to the cinnabar sacred stone offered by Jingzhou to the King of Zhou as it describes, "Tributes here are feathers, giant yaks tail, ivory and rhinoceros leather and gold, silver, copper, cedrela, cudrania tricuspidata, juniper tree and the cypress, rough stone, fine stone, stone arrow maker, cinnabar, Hu wood and slender bamboo. The three vassal states gave tribute to their treasures, wrapped up in bayberries and whiskers, colored silks in baskets and strings of pearls. Jiujiang tribute turtle." The Dan in "Xin Cai" is used with Huo" in combination, referring to the color of the coating, "As in the building of a house, where the walls have been laboriously built, it is necessary to consider the completion of the process of mudding and covering. Just like making catalpa wood implement, as we already peeled cut hard, should we consider to finish the job of colorful ornament."

In the Book of Songs · Zhongnan, "His face is red like covering with Dan. Is he my Lord?” which depicts the duke of Qin X iang with a radiance as rosy as water-soaked cinnabar. In Lv's Spring and Autumn, "The stone could be broken, but its firmness maintain. Dan could be grind but its will could not be deprived.” As a metaphor, it shows the historians' praise and admiration for Boyi and Shuqi's adherence to integrity. In Fan Zi Ji Ran, Fanzi said: "Yao, Shun, Yu and Tang all had foresight, so people were not in poor even there was crop failure.” King said: "Good. Use Dan to write on the silk, put it in the pillow, and cherish it as the treasure of nation.” The Dan mentioned above is cinnabar. In ancient times, cinnabar was a precious thing, often listed as the first tribute, the same as money in the market. In the Historical Records·Huozhi: "A widow in Bashu(two acient cities in Sichuan) name Qing, obtained Dan factory and exploited it in good way benefiting generations and earning good reputation for her family. Qing, a widow, could insist her course and used her wealth to defense for the country helping the nation stay away from invasion. The King of Qin treated her as guest, regarded her as loyal woman, and built a terrace name Huai Qing (memorizing Qing) Terrace for her.” 
The ancient encyclopedia of China, the Classic of mountains and seas, contains a detailed account of Dan. ${ }^{5}$ In Classic of mountains and seas · Hai Nei Xi Jing: At the east side of the enlightened god beast, there are Wu Peng, Wu Di, Wu Yang, Wu Lu, Wu Fan, Wu Xiang, they are around the body of Ya Yu (A mythical man-eating monster), holding the elixir against the dead and bring him back to life. Ya Yu, a monster with the body of snake and people face, was killed by Er Fu and his courtier Wei. In the Classic of mountains and seas Geography: "There was Ba people called Chi Hu (red tiger). He could refine cinnabar, took it with saltpeter. His body and hair are all red. The immortals call the elixir "Dan" or "Bao", and "Shi Wu"6 collecting elixir in Jiangling Mountain was considered the beginning of mining elixir. In the view of the scholar of immortals, all kinds of food taking (including fasting, promoting the circulation of Qi, guidance of Qi, internal alchemy, etc.), alchemy and witchcraft and various sacrificing can directly harness and control the forces of nature to serve their realistic and immortal purposes.

The name "Dan" is also commonly used in the traditional pharmacopoeia of doctors. This is because the ancestors of China were convinced that "Dan" had the power to help live forever. The originator of Chinese pharmacy, Shenlong Herbal Classic lists cinnabar as the first in the top grade, describing that it can cure "five internal organs of the body as well as hundred diseases, improve energy, anxiety-proof, enhance Qi, refresh eye, tranquilize mind, helping people to stay young if it is taken for a long time.” Therefore, in recipe of Dan in ancient pharmacopoeia, names of "Dan" are numerous, for example, Tian Wang Bu Xin Dan, Da Huo Luo Dan, Zi Xue Dan, etc. Dan is also a basic dosage form of traditional Chinese medicine (traditional Chinese patent medicine has four basic dosage forms: pill, powder, paste and Dan). To use cinnabar as coating, is to induce medicine into heart, and to reduce anxiety and calm the mind. In the prescription of traditional Chinese medicine, there are names like Zhu Sha, Fei Sha, Dan Sha and Chen Sha can be used as substitute to Dan.

In the "Yellow Emperor Jiuding Shen Dan Jing”, “Zhou Yi Can Tong Qi”, “Wuzhen”, “Bao Pu Zi”, “Ru Yao Jing”, “Xing Ming Gui Zhi” and other Dan classics, "Dan” naming is more complex, such as Zhen Dan, Jin Dan, Jin Hua, Qiu Shi, Huang Ya, Huang Ju, Huan Dan, Ling Dan, Shen Dan, etc. The Classic of Dan describes Dan made of herbs, trees, mountain stones and refined by fire in the stove as "Wai Dan" (external Dan). “Nei Dan” (interior Dan) is Dan that refined and stewed by human body's real fire in human's stomach (the furnace) with essence and energy from human body based on the principle of Qian and Kun (heaven and earth). ${ }^{7}$ The area where the Dan formed and stored is call Dan Tian (field). In the Zhong Lv's Preach: "Spirit, comes from Qi, is kept in upper Dan; essence, comes from Qi, is kept in middle Dan; essence, made from the combination of real water and real Qi, is kept the lower Dan. The upper field holds the spirit, the middle field holds the Qi, and the lower field holds the essence.”

The Yin and Yang experts, who advocate the five elements, regard the 'Dan' as a pure Yang, and compare the Yin and Yang to the ink chart and red paint. "Cinnabar is the essence of the sun and the substance of gold fire, connecting eight stone and following 24 solar terms.” Cinnabar is in deep red. Red means detaching. Deep red is Qian (heaven), the color of pure Yang in heaven and earth, which is enough to avoid Yin and evil. According to the yin-yang school, everything in the world is the result of the change of yin-yang, and the runes

\footnotetext{
${ }^{5}$ See Yuan Ke, Annotation of the Classic of mountains and seas, Shanghai: Shanghai ancient books press, 1980.

${ }^{6}$ The ten sorcerers of Lingshan are the ten sorcerers in the legends of the ancient Han nationality: Wu Xian, Wu Ji, Wu Pan, Wu Peng, Wu Gu, Wu Zhen, Wu Li, Wu Di, Wu Xie And Wu Luo, who are good at medical divination.

7 See Ren Farong, Interpretation of the Book of Changes Can Tong Qi, Beijing: Oriental press, 2012, pp. 23-25.

8 Taoist Collection, vol. 19, Cultural relics press, Shanghai bookshop, Tianjin ancient books press, 1988, p. 15.
} 
are more like "the natural Qi, forming the Qi into written form". Runes drew with cinnabar is runes painted with the pure Yang Qi of heaven and earth. "Dan” imitates the process of the origin of runes, so it has an inconceivable magical effect.

From the later Han dynasty to the northern and southern dynasties, Buddhism was spread eastward and interpenetrated with Chinese native culture. At the time of Song and Yuan dynasties, Buddhism originated from the emptiness of nature, and the thought of "knowing all things" and "understanding one's own heart" finally contributed to the integration of Dan Zen, which played an extremely important role in the formation of the internal Dan-system. It’s just like the saying in Zhi Xuan Ji: “The Buddha shares a family with all living beings, enlightenment was showed. The fish swimming along the net after nine returning and seven retrieving. Rabbit ran into net according to four Di (truth) and three emptiness. When will the chaos in the universe produce the results? Flowers grow again last night from the emptiness. Who was looking for Dan medicine in the tripod? The shadow of the moon slanted before the dead wood rock.” In the Buddhist sutras, there are also "Dan Tian", "Dan Xia" and so on. The ancient Indians called China "the true Dan", which can be found in the Mavtan Yashar and the Miscellaneous Abhidharma Da Bao Jing Juan, and other classics. In the As guardian of wisdom: "There is a country called great Han. When the sun rises on the east, its color looks like Dan. Therefore, it's erroneous to call it Sinian real Dan. Now that it's called Shen Dan, it's because it borrowed the pronunciation."

Ancient Chinese literati had always been fond of alchemy, and many of them were obsessed with it in the tang and song dynasties. A special stylistic classification called "Dan poetry" even emerged. Li Bai, Du Fu, Bai Juyi, Lu You and other great poets devoted themselves to the doctrine of immortality, made Dan poetry and carried forward the trends of Dan. In Li Bai's At the Terrace at Dawn: "Climbed the branches, picked the red fruits, burned the hot red furnace refining out the red medicine, in exchange for gold bone. How can I grow long feather on the body, so I can live in Penglai fairy island at ease for thousands of years?” In Du Pu's To friend in hunan, to express emotion while lying in bed in sickness of rheumatoid: "When it comes to family affairs, the technique of cinnabar could not be refined into gold, which make tears fall from my face once I think of it.” In Bai Juyi’s Drunk for the Failure of refining Dan, he complaint: “The white fair became shorter once there is autumn, and the cinnabar disappeared once there was fire. As I could not keep the mercury any more, I prefer to become an ordinary old man. The green material in the cup could not make my face turn red. The young don't have lofty ambition but makes himself half-drunk.” In Lu You's Hao Shi Jin, he sighed that: waved sleeves and left the world, flying along cliff to the sky, I found there was Dan Zao (cooking bench) of ancient immortal, where white cloud accumulating. My heart was calm like the lake without wind blowing. I had been sitting there for a while which is thousands of years for the human's world.

Dan is a kind of knowledge form peculiar to Chinese people. Things are named according to fact and grouped by categories. Classifying words from different periods and fields is very important to understand the generation, movement and deep framework of expression of this knowledge. To sum up, in terms of the existence and expression of "Dan" as a word, whether it is the yin-yang school, the immortal school, the historian, the medical school, the Taoist school, the Confucian school or the Buddhist school, although the "heart" and the "thing” are emphasized respectively, the knowledge order related to "Dan" is always connected with the isomorphic relationship between heaven and earth, body and mind, the form and spirit, and the life. As

${ }^{9}$ Electronic edition of the dictionary of Buddhism, http://foxue.51240.com/\%E4\%B8\%B9_foxue/ 
far as the meaning of the word is concerned, it can be roughly classified into the following eight categories by taking the existing object (the visible object), the perceived image (the sensible meaning) and the comprehend Tao image (the enlightened Tao) as the main points :

1. Cinnabar. Shuowen: Ba County and Nan Yue both produced cinnabar... Dan, the essence of stone. Book of Mountains and Seas · Da Huang Bei: "There was a Shizhou State, and there was a mountain of Dan there. In Xian Du Mountain: Emporor Huang visit the Bi Range which is the mountain top. Close to it, there was a Dan cave and the Jinxi River ran to the bottom.

2. Red, dyed pigment, painted and dyed red (moving). In the Rites of Zhou · Kao Gong: use red millet to dye the feather. The rites of ceremony - Xiang She Zha: all painting should have red quality. New Book of Tang: "forty thousand soldiers were killed and their blood dye the field in red." Also, Dan Que refers to the terraces on the both sides of the palace which are dyed in red. Dan Bi refers to the red steps caved with cloud; Dan Hao means red pen, etc.

3. Stars and directions. In Taiqing Stone Bi·You Fang: "Zeng Qing was the essence of the green loong cultivated with wood for the emperor at the east; cinnabar was the essence of red bird refined by fire for the emperor at the south...these five stones were essence of the five stars. In ancient times, there were five colors for five directions in the theory of five elements. The south direction belongs to fire, so its color is red (Dan) as fire, which is its meaning. In Yu Ji Qi Qian, vol 36: Dan, is the other name of the south.

4. Things belonged to the emperor, place where the emperor lived. "Dan Zhao" is the imperial edict of emperor. Dan Bi is the carriage for the emperor. Dan Jin is the forbidden city where the son of the heaven lived. Dan Shu Tie Juan (iron volumn with Dan letter) refers to the imperial edict issued by the emperor to his meritorious officials to enjoy the privilege of exoneration for generations.

5. Single or compound medicine agent. Supplementary Records of Famous Physicians: "cinnabar, as blood, calm bored mind, relief thirst, improve spirit,... help to relax.” Ben Cao Cheng Ya: As cinnabar can cure all disease, the other medicines can be abolished.

6. The Taoist. "Elixir” generally refers to the elixir of life. "Dan ding” is an instrument for refining elixir. "Danqiu", is the celestial realm in the immortal language. The 'Dan Zhuan' is the list and chart of Taoists. "Dan Tou" refers to the medicine used to enlighten the elixir when burning. Inner Dan refers to Qi of inherent Qingyang to remove Yin in the whole body.

7. Qi. Taoist Priest Bu Xu Ci: “All things come from the intangible, the Tao is the beginning of all spirits. With Dan Qi, comes from nothing, one can reach the palace of immortals.” Inner Qi is inner Dan. External Qi is called external Dan. The heart returns Qi, or Yin Qi and Yang Qi switching is called returning Dan; or internal and external Qi is called Jin (gold) Dan. ${ }^{10}$

8. A heart of absolute sincerity and loyalty. Cross the Ling Ding Ocean: Who can live forever? I will impart a Dan Xin (patriotic heart) to the annals of history. In the Gu Ying: "Now that I am alone going to vanish by myself, but my patriotic (Dan) heart maintains the passion." In Ming Xing Fu: "I was born as Chinese and died as ghost of Daming. I value my ideals more than my body.”

\section{The Physical Usages of Dan}

In the traditional Chinese cognitive system, things are not pure natural objects, but cosmic elements

${ }^{10}$ See Gong Pengcheng, A new theory of Taoism, Beijing: Peking University press, 2009, p. 208. 
closely related to the human life world. The so-called "observation and selection of images" is to use the natural nature or physical characteristics of objects to express the cognition and identification of life phenomena and life values. The Chinese ancestors raised the problem "physical" qualitative change of cinnabar to the "metaphysical" cultivation of the mind of Taoism of Dan. With Dan's function, change could be adopted.

(1) Implements of "Dan"

No matter for external use, taking food or refining, "Dan” as vessel, are all external things. In addition to the direct use of natural "Dan" (cinnabar), the ancient Chinese also used special technology to transfer the physical properties of cinnabar. The qualitative change caused by the human's interference is the boundary between Dan as the "supernatural thing" and the "refiner".

\section{Miraculous objects}

The natural physical and chemical form of Dan is Cinnabar, and its chemical composition is natural mercuric sulfide (HgS), which is an inorganic compound. Crystal cinnabar is called "Zhu Bao", and lung sand and dust sand are evaluated on the level of purity. In Song Yingxing’s Tian Gong Kai Wu Dan Qing in Ming dynasty, it writes: "the top Zhu Sha is produced from Chen, Jin and Sichuan. The middle level one is mercury which is not to used for refining. Gai Guangming, arrowheads, mirrors and other sand's value are three times higher than mercury, they will be selected as Zhu Sha for trading." The Wuling mountain ${ }^{11}$ area at the junction of Chongqing, Hubei, Hunan and Guizhou is the main producing area of cinnabar in China. Folk legend goes: "in ancient times, people caught fish and shrimps in a stream and found some red stones in the water. Ancestors grind it with stone into water which was like human blood, and drunk helping to relief anxiety and calm down.” The ancients regarded Zhu (red) color as blood and flame, symbolizing the constant pulse of life and the nobility and reverence of status. Color is invisible, it must be attached to the specific physical existence, so the stone was of divinity. The first use of cinnabar by the ancestors was the worship of heaven and earth and eternal energy:

(1) Funeral rites: cinnabar was used as early as the middle and late Neolithic period in China. ${ }^{12}$ From the Shang and Zhou dynasties to the Qin and Han dynasties, it was more common to spread cinnabar over the dead. ${ }^{13}$ The ancients sprinkled cinnabar on the body of the dead, said to give the dead new life. The phenomenon of painting human bones with vermilion is probably a kind of magic spell, symbolizing that white bones are recast into flesh and blood, so that the dead can reborn. And the burial objects painted Zhu was also very common, jade and bronze are mostly wrapped in Zhu Sha. ${ }^{14}$ People in Wuling mountain area still keep the custom of using cinnabar to paint on seven orifices and seal three souls and seven verve after death. When

\footnotetext{
${ }^{11}$ Wuling mountain is 420 kilometers long. The mountain ranges are in the east-west direction, and the karst landform is developed. The main peak fanjing mountain is in Tongren region of guizhou. Wuling mountain range covers an area of about 100,000 square kilometers, which is called wuling mountain area and spans four provinces of Chongqing, Hubei, Hunan and Guizhou. It covers an area of about 100,000 square kilometers. It mainly includes qianjiang district of Chongqing, Enshi Prefecture of Hubei province, Zhangjiajie city of Hunan province and Tongren district of Guizhou province.

12 Archaeology team of Qinghai provincial administration of cultural relics, Department of history and archaeology, Peking University, Preliminary harvest from the first excavation of Liuwan primitive society tomb in Ledu, Qinghai, Cultural relics, No.1, 1976, p. 67-78.

${ }^{13}$ See Brief report of Zhouyuan archaeological site (qijia village) excavation 2002, Archaeology and cultural relics, No.4, 2003. Excavation of Qin tomb in Yimen village, Baoji city, Archaeology and cultural relics, No.3, 1993. Pu Muzhou, Burials and death: reflections on ancient Chinese religions, Zhonghua publishing house, Beijing, 2008, p. 38.

${ }_{14}$ See Hu Jinzhin, Some issues on late shang burial system and burial customs in Yin ruins, Journal of Zhengzhou University, 2009, No.2. Erlitou task force, Institute of archaeology, Chinese academy of sciences, Excavation of erlitou site, No.3 and No.8, Yanshi, Henan, Archaeology, 1975, No.5.
} 
people died, the priest painted the coffin and the tomb with cinnabar to solitaire gas for new life and prevent ghosts from invading again; for those alive, the wizard use it to return worship or ward off evil, which could not achieved without Zhu Sha method implement and the charm guard body exorcism. ${ }^{15}$

(2) Taking the stone as medicine: in the book of Ji Jiong Zhou Shu, it is recorded that Bu people paid tribute to King Cheng of Zhou with cinnabar. "Fang people tribute peacock while Bu people contributed Dan Sha.” Legend has it that as early as the western Zhou dynasty, the ancients have begun to eat Dan stone. Nuo opera in Wanshan district of Guizhou province sings: "there was a woman whose surname was Fan, came to teach the local people to break the stone and take the Dan to present to the King. After taking Dan, King Wu of Zhou felt refreshed and wise. The king awarded Dan as secret thing and the place produced Dan as land for 'big longevity hill'. The The Yellow Emperor's Internal Canon of Medicine, Shenlong Bancao Jing and Compendium of Materia Medica recorded a large number of recipe of Dan, and proprietary drugs such as Liushen pill, Angong Niuhuang pill and Zai Zao pill, etc. There is a large proportion of cinnabar containing preparations in the total number of contents in the Chinese pharmacopoeia. ${ }^{16}$

(3) Writing and painting: cinnabar is not only the special pigment used by Chinese emperors, but also covers the whole history from oracle bone inscriptions to contemporary painting and calligraphy. Cinnabar was widely used in inscriptions on red inscriptions on oracle bones painted on red clay in Yin ruins, "longivity star" runes in anyang Dan calligraphy, vows in Houma Dansha, Huashan rock paintings in Guangxi, mural fragments in the imperial palace of Qindu, and Buddha murals in grottoes (Mogao, Maiji mountain, Yungang, etc.). ${ }^{17}$ Cinnabar has always been known as the "three major colors" of Chinese traditional painting together with the stone Qing and the stone green.

(4) Painted pottery lacquerware: Chinese ancestors mastered the art of painting painted pottery and making lacquerware since the Neolithic age. Cinnabar was used as an important raw material for the coloring of grey pottery urns in Qinan Dadi Wan of Gansu province, terracotta warriors and horses of the first emperor of Qin, lacquer bowls of Hemudu, wooden wares of Liangzhu and lacquered coffin-cases of Han tombs in Qufuchai valley. ${ }^{18}$

(5) Textile makeup: the ancient Chinese textile printing and dyeing is a wonderful work of art, in which Zhu Sha plays a very important role. Chensha fabric of Liujiahe in Shang dynasty ${ }^{19}$, Mawangdui "Zhuhongling Silk Brocade Robe” and "painted Fei clothes” (silk drawing of T shape) are all dyed with cinnabar. ${ }^{20}$ Women

\footnotetext{
15 The data comes from the author's multi-point field survey report of Chongqing, Guizhou and Hunan regions from July 2013 to November 2014.

${ }^{16}$ Chinese herbal preparations containing cinnabar accounted for $8.71 \%$ in the 2005 edition of the Chinese pharmacopoeia, $14.5 \%$ in the 1985 edition, and $13.7 \%$ in the 1963 edition. See Li Ping, Research on traditional Chinese medicine cinnabar, west China medical journal, 2010, 5 (6) : 622.

17 See Excavation report of Yin ruins from 1969 to 1977, Journal of archaeology, No.1, 1979, P. 27. Pan weibin, Archaeological harvest in Gu'an project, Anyang City, Henan Province, China cultural relics daily, 5th edition, March 16, 2007. Wang Bomin, General history of Chinese fine arts, Jinan: Shandong Education Press, 1987, p. 263.

${ }_{18}$ See Ma Qinglin et al. Analysis and research on colored pottery pigments and block pigments unearthed from qinan dadi wan site in gansu province, Cultural Relics, 2001, No. 8, P. 84-92. Lande Province, The practice of cleaning painted terracotta figures, Proceedings of the third annual conference of the Chinese association for the protection of cultural relics, 2005, p. 98-104. Chen Yuan-Sheng, Xie Yulin. Research on analysis and identification technology of prehistoric paint film, Cultural relic protection and archaeological science, 1995, No.2, p.12. Wu Shuangcheng et al. Analysis and protection of painted coffin-paintings unearthed from han tombs in Qufu Chai Yu, Proceedings of the third annual conference of the Chinese association for the protection of cultural relics, Beijing: Forbidden City press, 2005, p. 71-77.

${ }_{19}$ Chen Weiji, History of Chinese textile science and technology: Ancient parts, Beijing: Science Press, 1984, p. 30-32.

20 See Cultural relics research group of silk industry corporation, Shanghai textile research institute, Research on unearthed textiles from No.1 Han Tomb of Mawangdui, Changsha, Beijing: Cultural relics press, 1980, p. 82-84.
} 
in the western Zhou dynasty initiated the fashion of "Dan point" (red spots). After the eastern Han dynasty, vermilion lipstick was popular among women. And the lipids unearthed from Huohe tomb in the western Han dynasty were also confirmed to be natural Dan Sha by identification. ${ }^{21}$

\section{Implement of refining}

The essence of a refining device is that the ancients attempted to transform the eternal energy contained in the Zhu Sha (natural thing) into an artificial thing, that is, "transform what the nature has into human use."22 From object to organ, "Dan” has gone through a complex evolutionary process. Although gold refining, melting into mecury, Dan returning are based on the elixir of life, and are technical practice based on the cognitive system of "things can change, change is infinite", the "system" and "usage" of its metaplasm are quite different.

(1) Alchemy: alchemy originated from the magic skill of the gods of Yanqi. In the Records of the History·Fengchan, Li Shaojun suggested to the Emperor Wu of Han: "Sacrifice to the kitchen god can attract strange things, attracted strange things can make red sand into gold, can prolong life, can see the immortal Penglai.” The initial idea of taking alchemy is to create a sacrificial vessel for food and Fengchan (offer sacrifices to heaven), in order to connect heaven and earth ancestral society. In the later Han dynasty, Liu An, King of Huainan, gathered thousands of people and wrote more than 200,000 words in the Huainan Honglie, but he changed his original intention, "to explain the technique of gods turning strange things into gold", trying to convert base metals such as lead, mercury, copper and iron into gold and silver. Since then, the knowledge and practice system of "technique of gold and silver" to smelt alloy has become a big branch of Chinese foreign studies.

(2) Melting into (Hong) mercury: "Hong, mercury melted from cinnabar." The ancients realized that mercury had a better antiseptic property than cinnabar ore powder, and could protect the body and soul. Because natural mercury is difficult to obtain in large quantities, so the main rely on cinnabar stone refining. According to the research, the tombs of Duke Huan of Qi and Helu in the spring and autumn period all "poured mercury into the pool”, ${ }^{23}$ the First Emperor of Qin’s Lishan tomb was infused with mercury to form rivers and ocean with the upper part of the sun the moon and the stars pattern and the lower part of waters and mountains patterns." ${ }^{24}$ The medicinal value of mercury was also fully affirmed by ancient doctors, and it was regarded as a good medicine for removing putrefacient muscle and removing inflammation and killing toxin. As early as the Han dynasty, the Chinese mastered the art of gold plating with mercury, "Apply the mixture of gold and mercury evenly on the surface of the object, which is white. Put it in a high temperature fire. The mercury fades, and the gold remains. Repeated many times, yellow color on the surface gradually becomes obvious.”

(3) Huan Dan (return into elixir): The historical mainstream of alchemy revolved around the magical "reconversion" between cinnabar and mercury. Before the end of the Han dynasty, "returning into Dan" became the key to ascend the celestial being, marked by the birth of "the Yellow Emperor Nine Tripods Shen Dan Jing Jue”. Gehong’s explanation of "return into Dan” is simple and clear: "cinnabar burned into mercury, then change into cinnabar. Refining and returning into Dan, is refine natural cinnabar into mercury, and the mercury is mixed with sulfur and refined into pure mercury sulfide in a sealed pot. Mercury sulfide is refined into mercury by adding lead or other drugs, and "elixir" is refined repeatedly. From "being immortals from

\footnotetext{
${ }^{21}$ Brief on the cleaning of huohe tomb in the western han dynasty, Archaeology, No.3, 1974, p. 174-186.

22 Qu wanli, “The book of history,” Taipei: Commercial press, 1969, p. 22.

23 [Tang] Ouyang Xun. Collection of literary and artistic works, Beijing: Zhonghua publishing house, 1965, p. 141.

24 Records of history, First King of Qin (1972), Beijing: Zhonghua publishing house, p. 2911.
} 
gold" to "being immortals from Dan”, the concept of returning Dan is an important reform of ancient magic of immortals technique. Also Tang dynasty was the peak period for "Huan Dan”, many schools emerged with numerous laws, but it also began to show a large number of harmful side effects of external Dan. According to Zhao Yi's notes on the Twenty-two historical notes, there were as many as six emperors in the tang dynasty died due to taking Dan. Since then, alchemy began to focus on metaphysical speculation looking inward, and there were various internal Dan theories of Qi cultivation, which was used to distinguish from the gold and stone refining technique. Dan's theory and technique took an important turn since then.

(1) Dan of Taoism

In Bai Yuchan's Fu of the Gold liquid turning into Dam, the logic relationship between the Tao as the goal and the Dan as the means is summarized with "great principle is beyond words and internal alchemy is more than technique, ${ }^{25}$. From a historical perspective, the formation of the ancient Chinese thought of Daoism is closely related to immortals, skills, medical classics, sexual intercourse and yin-yang. On the one hand, Daoism was introduced in Taoist context, and it was believed that people could grasp the function of the physical universe through practice, exceed the opposition and restriction of time and space, and achieve the ideal of "both shape and spirit are refined". On the other hand, with Confucianism and benevolence, human ethics will be promoted to the realm of sages and become the true knowledge of "having sage's virtue inside while implementing the rules outside"; After the Song and Yuan dynasties, it also participated in the theory and method of enlightened mind of Zen Buddhism, and advocated the wisdom of "double cultivation of life and soul”. "After Can Tong, cultivating oneself to become an immortal was called alchemy Taoism; from Bao Pu to all scholar, they read books of Dan."26 Its essence is to solve the problem of life and death of people, showing the value of human life as the core of reflection and get through.

1. Both form and mind being refined

"Both form and mind being refined" is the traditional Chinese theory of life cultivation and the dharma image, it makes the Dan technique rise from the "physical" practice to the "metaphysical" system. The early Chinese concept of form and spirit was greatly influenced by the immortals and Taoists, which believed that if the form is separated from mind, one will get sick, become old, and die. The immortal theory of "body immortals" regards both "form" and "god" as different forms of "Qi", and emphasizes that only through refining and nourishing the essence of life, can the form and mind be united and achieve the ideal of body deathless and immortal life. Bao Pu Zi Nei Pian Zhi Li writes that In Mi County, Henan province, there was a man named Bu Cheng. He had been learning Tao for a long time, so he left with his family. His first step was slightly higher, then went into the cloud and disappeared. This so-called lifting the form and flying light into the sky during daytime, becoming the top immortals."27

After the introduction of Buddhism, the goal of physical immortality was gradually abandoned and replaced. People began to realize that "form will eventually vanish, but the consciences of immortal is infinite". The concept of form and spirit sublimates to a new level: from maintaining the invariability of form to making form transform, and then to the state of "form and spirit as before" after transformation. After liberation, the concept of "both forms and gods are refined" has gone from "eternal body" to "invisible true body", not

\footnotetext{
${ }^{25}$ Taoist collection, vol. 33, Cultural relics press, Shanghai bookshop, Tianjin ancient books press, 1988, p. 146.

${ }^{26}$ Lu Jinchuan, Talking about Tao from the perspective of Buiddism: three cases and five secrets, Beijing: Huaxia publishing house, 1997, p. 172.

27 WANG, Ming. Revised edition of Bao Puzi Nei Pian. Beijing: zhonghua publishing house, 1985, p. 115.
} 
clinging to the tangible body of the day rise. Instead, the "Yang god" with Qi of unity is regarded as the Dharmakaya and dharma-laksana of the "immortal”. In Shang Yang Zi Gold Dan Cartridge IV, "all things in the world are no more than three things: Shen (spirit), Qi, essence (Jing), which react with each other. If the process goes in order, there will be the birth of human, vice versa, there is Dan. What is process in order? One generates two, two generates three, and three generates all things. Therefore, emptiness turns into spirit, spirit turns into Qi, Qi turns into Jing, Jing turns into form, and form turns into human being. What is process reversely? All things contain three, three returns into two, two returns into one. Those who knows this principle is pleased to keep the form, raise the form and refine the essence, gather and refine the spirit, refine the spirit and combine with the mind. Cultivate mind into emptiness, and therefore the gold Dan is produced." ${ }^{28}$ The contract of form and spirit is based on "emptiness", but "emptiness" is not the same as nothing, but the transformation of the form of life and the truth of Tao. Mind can be not enlightened, but form cannot be unborn, "emptiness without stagnation beyond life and death" is the ultimate destination of human immortality. ${ }^{29}$

\section{Cultivation of spiritual and physical life}

If the cultivation of the spirit of form is the practice of human on the level of life phenomena, then the practice of life is the application of the essence of life. Since the Song dynasty, due to the influence of Buddhism, the understanding and interpretation of body and mind, form and spirit, and life and death began to change. The Ming Gui decree Life explains: "What's nature? It's the real origin, the bright mind. What's is life? It's the endowed Yuan Jing, the Qi filled in the body. Nature for the heart, it's the mind of spirit. Life for the body, it's the circulating Qi.”30 The cultivation of nature depends on the heart, and life depends on the body. To transform "form" depends on the effort of life, while returning to the origin the source relies on is the effort of nature. "Coordination between spiritual and physical life" is means and the goal of spiritual awareness. It changes the "solid form" of Dan Gong into "coordinate with Tao", evaluates the life status from the perspective of the universe, and endows life with value.

The traditional life science of Daoism has historically been divided into north and south schools. The southern school focuses on cultivating life, while the northern school focuses on cultivating nature. The beginning of the processes for these two seem different, but they blend with each other. That is one is not one, and it's two but not two. Those who cultivate life, their lives establish and spirits are enlightened; for those who cultivate nature, their nature retains and lives last. The nature of Coordination between spiritual and physical life is called "cultivation of the mind and nature" by Taoism, "enlightening mind the nature” by Buddhism, and "maintain the mind and cultivate nature" by Confucianism. The best Dan method in Zhong He Ji is as follows: "the best method is the supreme truth. Use Taixu as the tripod, Taiji as the furnace, and pureness as the base, and inaction as the parent agent, and life as lead and mercury, calmness and wisdom as water and fire, desire and punishment as infusion of water and fire, the unity of nature and character as gold and wood, clearing heart and concerns as bathing, and remaining honesty as foundation consolidating. Moral cultivation, heartsease and wisdom cultivation are the three key elements. Xuan Guan is a the middle. Enlightening mind is to verify. Revealing the nature is to condense results. The three elements mix into a saint embryo, while the nature and life mix to complete the production of Dan. Escaping embryo refers to body outside the body, breaking through

\footnotetext{
${ }^{28}$ Hong, Peimo., Ed. “Essential works of Qi Gong in Taoist culture”, Shanghai: Shanghai bookstore press, 1991, p. 1856.

${ }^{29}$ See Meng Wentong, the Edited ten types of books on tao, Cheng Xuanying of Tang dynasty, Interpretation of moral classics, Chengdu: Bashu publishing house, 2001, p. 387.

30 Tianyuan Dan Fa, Gui Zhi of Life, Beijing: renmin university of China press, 1990, p. 79-80.
} 
the emptiness. This is the best method which can be practiced by supreme scholars. When all the effort complete and virtue are highly spread, one made more effort than the cultivation, achieving coordination of form and spirit and unifying the nature with Taoism. ${ }^{31}$ The essence of Dan is to unify the isomorphism of the life cultivation of "action" and the nature cultivation of "inaction", go beyond the "ego", and break the "emptiness" until the completion, as it's said that "Dan is the most valuable treasure for the body. Its change is infinite once it's completed. It also explores the real origin in addition to the nature, taking advantage of the emptiness."32

\section{The Philosophical Connotations of Dan}

In the name, object and principle of "Dan”, Chinese people's understanding of truth, goodness and beauty is included. Between things and non-things, as the holy things that condense the essence of heaven and earth, Dan is not only the survival philosophy and life science passed down from generation to generation for thousands of years in China, but also the life aesthetics accompanied by the present reality. The "connotation" of Dan is the root of the hidden faith; The "philosophy" of Dan is the manifestation of the principle. To the Chinese, it is universal and objective, the essence, effort and realm of life.

(1) The hidden connotation

Most of the philosophical and religious thoughts in the world stand on the other side of death and call for soul sublimation. However, the true transmission of the principle of Dan is contrary to those thoughts, carrying and expressing the Chinese tradition of "valuing life". The word 'value' originally meant high rank title of nobility. The meaning of superior is what came later." and "sage thinking about the world, nothing is more valuable than life." The book of changes writes: "vivid life is the principle." Taoism takes "life" as another form of Tao. Mohist said, "nothing in the world is worth than life." All these expressions show that "life" is the highest value for Chinese people. "Lfie" not only refers to living, but also includes the processes of generation, reproduction, growth and biochemistry. "Vivid life (Sheng Sheng)" emphasizes the meaning of Yin and Yang complementing each other, constantly changing and harmonious coexistence, which is people's profound understanding and interpretation of life in the universe. As a common theoretical model of internal and external Taoism, "to obtain Tao in life" is committed to the belief of "celestial being" from beginning to end, and is built in a structure based on "Dan-immortal-Taoism".

1. Core: immortal

There were many legends about immortals in ancient China. In Zhuangzi Xiao Yao You: "In the Maogu Montain, there was an immortal who has white complexion and was quite. She didn't eat grains but rain and wind, rode on the cloud and flying loong, and traveled all over the world.” In Qu Yuan's She Jiang, he sang "riding on the green Qiu and white loong, Chonghua and me travelled in the garden of Yao. Walking to the Kunlun Mountain, eating jade, I can live as long as the heaven and earth and give out light like the sun and the moon.” In Liezi Tang Asking, “Among them, there was a jade mountain, ... all are gold and jade on the platform and birds and beasts are dressed in pure silk. Tree of beads were growing everywhere with delicious fruits which once taken could help people stay from aging and death. Numerous people living there were all

${ }^{31}$ Xu Zhaoren, Ed. Tianyuan Dan fa (the library of Oriental monasticism), Beijing: renmin university of China press, 1988 , p. 26.

32 Zhang Jiyu, Chinese Taoist collection, vol. 19, Enlightened by the Truth: West Lake Moon, Beijing: Huaxia publishing house, 2004, p. 451.

33 Zhang Dainian, Complete works of Zhang Dainian, vol. 6, Shijiazhuang: Hebei people's publishing house, 1996, p. 97. 
immortal and saints. They flew forth and back in day and night. As immortal enjoyed longevity, Guangchengzi lived for two thousand and two hundred years, Peng Zu lived for eight hundred years; Fairyland was beautiful, the treasure covered the stage. It was bright in four seasons. The pursuit of freedom and happiness is human nature. Since gods and men are interlinked, gods and goddesses can learn from each other and live a long life. Therefore, the theory of immortal continued, immortal art is bound to emerge in an endless stream, and the immortal method last for a thousand year.

In Name explanation · old and young, "people who didn't die even he is old is called immortal." The theory of immortal values life, enjoyment of life, rebirth of life, and pursue of longevity. Its essence is "life first"; the art of Dan takes "stealing, seizing, saving and understanding” ${ }^{34}$ as the means of maintaining one's health, namely applying Tao to the body, with its goal to "expand life and cultivate nature". For the nature of Dan's physical usage and cultivation, from primitive thinking to worshipping things and belief, to philosophical system and religious attachment, it cannot be separated from the word "immortal". Chinese people believe in immortals, but the relationship between human and gods is not one of "blessings". As "Immortal is the supreme goal of refining" ${ }^{35}$, life can be enabled to achieve the realm of "true immortal" through the effort of Dan. Major scholar of theory of immortals pointed out that since ancient times, people who learn to be immortal must start from alchemy. No alchemy, no immortality. ${ }^{36}$ As it is said that "ten thousand volumes of fairy scripture are the same, only the gold Dan is the root." ${ }^{\text {37 }}$ Although the internal art of Dan values more on becoming immortal by the spirit going out from the body, the external art of Dan emphasizes on the form and body being returned into the nature. However, this is only the difference in the technical paths. "Alchemy" and "immortality" are mutually cause and effect. "Immortal" is the core of the belief in the theory of Dan that being immortal even one is old while taking advantage of its true emptiness and achieving the coordination of human and the heaven.

\section{Structure: Dan - immortal - Tao}

The immortality cannot exist independently without Taoism, and Taoism is more effective because of the immortality. In the Vipassana of the very high lord: "Tao is invisible but clear due to life; as there are changes in life, we should maintain it with Taoism. If life ends, Tao is abolished, vice versa. Life and Tao combine as one, and life lasts without death, one can become immortal."38 In the Introduction to the Celestial theory, "Tao is the principle for people to maintain life. Tao is used to cultivate life, which is explained that Jing, Qi and Shen (spirit) are cultivated in life as human's body. Therefore, Jing, Qi and Shen are cultivated into human, namely Tao cultivates human.” The cycle theory of vitalization-concern of body-metaplasia is attached to the Taoist method of "Dan", which not only embodies the life model of Chinese people of high Ideology, but also embodies the cognitive tradition of Embodiment. From the beginning of Yellow Emperor's transforming Jing into Qi, to Zhunagzi’s "Stretching exercises", "get rid of the stale and take in the fresh" and "eliminate distractions”, Wei Boyang’s "learning from the similar”, Ge Hongtao Hongjing’s "cultivation of the mind" and "maintaining one and reserve Jing”; to Sima Chengzhen’s "cultivating mind and spirit to connect with Tao",

\footnotetext{
34 In Tang dynasty, Cui Xifan's "Ru Yao Jing” was an important work of Chinese internal medicine cultivation. See Zeng Zao:Daoshu, Shanghai: Shanghai ancient books press, 1990, p. 394.

35 Orthodox Taoist collection, (compact copy, Taiwan art press) volume 39, the Two-phase Xiang Shu of Dachaoshi, 1976, p. 31476 .

${ }^{36}$ Tien cheng-yang, ed. Elaboration on the study of celestial being. Beijing: religious culture press, 1999, p.186.

${ }^{37}$ Wang Mu, a brief introduction to the Book of enlightenment, Beijing: Zhonghua publishing house, 1990, p. 175.

38 Zhang Jiyu, Chinese Taoist collection, vol. 6, Beijing: Huaxia publishing house, 2004, p. 80.
} 
Zhang Guo and Zhong Liquan's “culticating Qi to produce Dan”, Tan Xiao’s “form can be unborn and mind can be unenlightened”, Cui Xifan's “my heart as mirror and my body as table”, to Zhang Boduan's "cultivation of both life and nature", the history of Dan shows the combination of "enlighten mind to find the nature" and "cultivating body" incisively and vividly.

The three stages of "Dan”, "immortal” and "Tao" demonstrate the cultural structure system of Dan from the traditional perspective - heaven and earth are called Tao, and the celestial being is where its cultivation mechanism is located, and its divine use is shown in Dan. First of all, cinnabar is the substance of heaven and earth. Because of which the color of red, it is characterized with divinity and became the original substance representing the energy of the universe. The process of Dan art carries the belief of immortals in the way of technical practice and extends the divinity of red cinnabar to Dan medicine. The sense of Dan Tian has abandoned the material meaning of cinnabar and made it an abstract understanding of vitality. The meaning of Dan Xin (sincerity) further elevates the change to the level of "Tao". Cinnabar eventually became the symbolic concept of the ancient Chinese saying "heaven and earth coexist with me, and all things are one with me". The structure system of "Dan - immortal - Tao" not only extremely explored the theory of heaven and earth's application, but also clarified the opportunity of using mind and body to learn the virtue and understand the feelings of all things.

(1) Principle of manifestation:

The theory of manifestation is the narration, explanation and correction of hidden meaning. On the one hand, the material, technology and belief of Dan influence each other and become a typical local knowledge system through practical activities. People take it as the guiding principle of life and inherit it from generation to generation. On the other hand, the cognition of the other people and the relationship between interests kept bumbling over, and complicated and changeable environmental dominant factors came into being, making Dan's life course, ecology and the reality of life difficult to hold on in the turbulence.

\section{Principle: practice connect with the heaven}

The essence of the behavior of collecting and alchemy is the worship, imitation and realization of the order of the universe by the Chinese ancestors. For the sake of survival, the ancestors continuously discovered and utilized all kinds of energy contained in nature. But in this process, they always emphasize the coordination of natural force (natural work) and artificial force, and the coordination of natural behavior and human activities. Technology becomes a form of integrated practice of spirit - harmony with Tao, and practice connect with the heaven. As a result, the Chinese move back and forth between the sacred and the profane, handling, controlling and rhythmically managing all affairs related to Dan in complex rituals:

(1) Collect Dan to offer sacrifice: Guizhou Wuchuan has been called "cinnabar ancient county". The inhabiting Yilao person mostly collected Dan for a living. The people collected Dan believed that Baowang was the bodhisattva who blessed them to collect " high purity cinnabar ore” and honored it as the god of ancestors and industry. There are three forms of worshiping bodhisattvas: annual sacrifice, big sacrifice and small sacrifice. In small sacrifice, pig's head is used as a sacrifice, people mining Dan asked Baowang in front of their own mine cave and prayed. The big sacrifice is to redeem a vow: "Baowang bodhisattva bless me to collect high purity cinnabar. If so, I will offer you a pig's head.” The annual sacrifice is at the eve of the New Year, the fourteenth day of the first lunar month, Chinese Halloween and other festivals, when people burn 
incense paper, but would not offer pig head. ${ }^{39}$ With the belief of Baowang, the people who collect Dan consciously formed a sense of reverence for nature, and mined cinnabar in a temperate way. At the same time, it also actively generates the ownership and constraints of the industry, creating proper measures of ownership awarding.

(2) Alchemy working procedure: according to the literature of alchemy, the working procedure is orderly and complicated. The first is to build an altar of Dan in certain format. "The rule of tripod and vessel must be followed. There are also high and low, size, narrow, weight, thickness, depth, that should be carefully investigated and made to fit the true text. It could not be done without following rules. ${ }^{\circ 0}$ The second is the timing. "Take the sky as the tripod, the earth as the furnace, and take advantage of the moon mining according to full moon and wanes. The sun is the fire, and the sun is the sign of activity. From the beginning to the end, all should follow the heaven and earth." ${ }^{, 11}$ The requirements for participants were even more stringent. "People who smash drug should be more discreet and less talkative. When the 30 days of fast complete, they went to another room, cleaned their clothes and bathed. Three or four people can cooperate with joint effort, and stayed in calm mind. The taboo laws is just like the fast. ${ }^{\text {} 42}$ The connotation of process, instrument and system are clear: human's Dan proess follow the law of heaven and earth as well as its principle.

\section{Bhuta-samjna: follow Dan for life}

Starting from the belief, Dan's collecting and eating is the formalized expression of people's spiritual world. As far as technology is concerned, this series of behaviors are the specific technological activities of people. From the material point of view, Dan and its derivatives are the daily needs of people's survival. People took Dan as career, improve livelihood, build cities and state. With Dan Xin (sincerity) in mind, people understood life and death, knew their ancestors and origin, and proclaimed Buddhist.

(1) Take Dan as career

In Yizhoushu · king's meetingi, King Cheng of Zhou met vassals, "Shu people offer literature, Ba people offered inseparable king bird, Bu people offered cinnabar. Those who offered Dan also collected Dan and lived by Dan. Therefore, "Dan" has become a symbol for foreigners to identify Bu people. According to the note: "Bu people, barbarian at the southwest where cinnabar was produced." According to the research of scholars, the origin of Ba people is also deeply related to cinnabar: Linjun with surname of Ba was born in "red cave" (namely Dan cave). Ba people relied on Dan mining for a living, and founded the cause as they benefited from salt spring. ${ }^{43}$ In the Guizhou Pictures Xin Zhi · Customs at the House of Sinan during Jiajing of Ming dynasty, it describes that Wuchuan people live by collecting Dan, "the pit was about four or five or six miles deep. Residents with a leather hat, hanging lights in the forehead, went into the mining, and went out after the night... Residents depend on it for livelihood, annually offered 160 jin as tribute. It was often used in trade as notes of denomination of thousands.” Qing Guangxu version of "Xiushan County Records” : “factory, household traffickers traded outside the country, and gained benefit of millions of gold. While promoting social division of labor in Wuling mountain area, cinnabar economy also makes traditional settlement mode begin to change.

\footnotetext{
39 The data comes from the author's field survey of Wuchuan county, Zunyi city, Guizhou province from October to November 2014.

40 Taoist Collection, Vol. 22, Cultural Relics Press, Shanghai Bookshop, Tianjin Ancient Books Press, 1988, p. 338-339.

41 See the Can Tong Collectiona and Notes, volume 9, edited by dong peiwen, Beijing: Religious Culture Press, 2013.

42 Taoist Collection, Vol. 22, Cultural Relics Press, Shanghai Bookshop, Tianjin Ancient Books Press, 1988, p. 470.

${ }^{43}$ Liu Buxiu, "the resources background of the primitive nation choosing the three gorges settlement: salt and cinnabe construct the two pillars for the survival and development of the ancestors", China three gorges construction, no.3, 2003, p. 45.
} 
Since ancient times, Chongqing, Hubei, Guizhou and Hunan have taken "Dan" as the name of their mountains and rivers. Capital of Chu was Danyang city, which was moved to Ying later. In the sixth year of the eastern Han dynasty, Danxing county was set up to mine cinnabar. Wujiang in ancient times was called Dan Fushui, also known as Dan water, as it was used to to transport cinnabar; In ancient times, there was Danyang mountain in Pengshui. The official of Qi of Xia, Mengtusi Shenyuba lived in Dan mountain. And the official management of cinnabar resources emerged as earlyas Qin and Han dynasties. ${ }^{44}$ In the "peace and the universe" in song dynasty, most Yi people took cinnabar and mercury as tributes. "Guizhou, cinnabar; Fengzhou, bright sand; Feizhou, cinnabar; Sizhou, cinnabar; Yuanzhou, cinnabar; Yezhou, cinnabar. These six states produce cinnabar." Until the Ming dynasty, the tussle between the local officials and the central government for the cinnabar resources directly led to the abolition of the (Tu Si) land official system. Removed the department, built government house, change the land official system and turned back to the bureaucratization of native officers. ${ }^{45}$ As a source of food and clothing, "Dan for industry" is an important economic production mode of the indigenous people. The fluidity brought by "taking Dan as the industry" has also become an important factor in the construction and reconstruction of political relations among Chinese and foreign people.

(2) Holding Dan in the heart (keeping a sincere heart)

For the elite of the Han culture, the science of Dan is the mainstream and prestigious doctrine based on Confucianism, Buddhism, Taoism faith as the core, combining the practice of other schools, ritual system, and moral ethics. Dan not only constructs the immortal edifice of their spiritual thoughts, but also creates a spiritual home for them to transcend themselves and pursue eternity. Although the journey of alchemy and immortal cultivation, consciousness of life is a long and difficult: The first is to be insightful, to figure out Dan's theoretical system; Secondly, it is necessary to have cultivation and certification, to know how the key of the Dan principles and get the experience of alchemy; What is more important is to practice the wish, that is, to have a sincere heart, perseverance and vows. But Dan and balance in mind still become the realm of life that the Chinese intellectual elite devote all their life to. In thinking about the existence of life, the essence of life and the meaning of life, Dan principle has become the highest spirit and highest taste of Chinese traditional "metaphysical" culture. But in the folk, the "physical” Dan and reality can still be seen everywhere. They use object to reflect the principle, apply technique (Shu) to reveal the principle and to develop it from generations to generations. People in Wuling mountain area regard cinnabar as holy objects and depend on each other for life and death. In their mind, cinnabar is the lamp of another world. Without cinnabar, there is no way to "go home (land of ancestors' spirits)". Therefore, they often add "terra cotta” (vermilion powder) to traditional food. Generally, cinnabar is used as paint decoration in residential buildings. After the elderly dies, the tomb is sprinkled with cinnabar as they install tombs, connect Qi of dragon thus to benefit the descendants. Old people always admonish posterity: "received rice and oil in hand, be inferior to putting cinnabar in the heart." ${ }^{\text {"46 }}$ From

\footnotetext{
44 "The Classic of mountains and seas · the great wilderness in the west" : "there was wushan mountain. There were yellow birds in the west, eight Zhai of emperor medicine. There were yellow bird in wushan, guarding it from mystery snake.” According to the research of Mr. Yuan Ke, the yellow bird is the emperor bird, and the "guard wushan on duty" is a metaphor for the Wu state to sent officials to guard the Dan mine and prevent others from looting.

${ }^{45}$ In the middle and later period of the Ming dynasty, the chieftain of Tusi was abolished and replaced by officials appointed by the central government. This highly centralized political measure accelerated the process of the transformation of the remote areas of ethnic minorities into the political, economic and cultural subjects of the state, which was a significant historical practice of "the unification of the imperial geography".

${ }^{46}$ Hu Fuchen. Introduction to the principle of Dan and technique of immortalization. Beijing: Social sciences academic press, 2009, p. 230.
} 
"the principle of Dan" to "the soul of Dan", the treatment, reflection and interaction of the two have contributed to the collective memory and identity of Chinese people. Holding Dan in the heart, as a kind of spiritual conversion and internalization of knowledge, guide the Chinese nation to correctly deal with the relationship between man and nature, man and man, body and mind, and reproduce and prosper till now.

To sum up, the prominent universal value of "Dan" as a cultural heritage is, on the one hand, its native and special ecological cognition and life belief-respect for heaven and earth, correct life and improve body and mind; Second, the collective memory and cultural identity of the multi-ethnic cultures it carries-Sinicization, barbarization and assimilation; Third, it solidifies the brilliant and magnificent historical relics and cultural symbols - fairy wonderland, land for Dan collecting, Chinese red. "Dan" creates, carries and reflects the thinking logic, perception mode and living habits of Chinese people. It is the most important and rich "home heritage" of Chinese traditional culture.

\section{References}

Peng Zhaorong: Home heritage: anthropological perspective of modern heritage science, Journal of Xuzhou Institute of Engineering, 2013

Taoist collection, vol. 19, 22, 33, Cultural relics press, Shanghai bookshop, Tianjin ancient books press, 1988

Yuan Ke: Annotation of the Classic of mountains and seas, Shanghai: Shanghai ancient books press, 1980

Ren Farong, Interpretation of the Book of Changes Can Tong Qi, Beijing: Oriental press, 2012

Electronic edition of the dictionary of Buddhism, http://foxue.51240.com/\%E4\%B8\%B9_foxue/

Gong Pengcheng, A new theory of Taoism, Beijing: Peking University press, 2009

Chen Weiji: History of Chinese textile science and technology: Ancient parts, Beijing: Science Press, 1984.

Qu wanli: The book of history, Taipei: Commercial press, 1969.

[Tang] Ouyang Xun: Collection of literary and artistic works, Beijing: Zhonghua publishing house, 1965.

Records of history, First King of Qin (1972), Beijing: Zhonghua publishing house.

Lu Jinchuan: Talking about Tao from the perspective of Buiddism: three cases and five secrets, Beijing: Huaxia publishing house, 1997.

WANG, Ming: Revised edition of Bao Puzi Nei Pian. Beijing: zhonghua publishing house, 1985.

Hong, Peimo: Ed. Essential works of Qi Gong in Taoist culture, Shanghai: Shanghai bookstore press, 1991.

Meng Wentong: the Edited ten types of books on tao, Cheng Xuanying of Tang dynasty, Interpretation of moral classics, Chengdu: Bashu publishing house, 2001.

Tianyuan Dan Fa, Gui Zhi of Life, Beijing: renmin university of China press, 1990.

Xu Zhaoren:Ed. Tianyuan Dan fa (the library of Oriental monasticism), Beijing: renmin university of China press, 1988.

Zhang Dainian: Complete works of Zhang Dainian, vol. 6, Shijiazhuang: Hebei people’s publishing house, 1996.

Zeng Zao: Daoshu, Shanghai: Shanghai ancient books press, 1990.

Orthodox Taoist collection, (compact copy, Taiwan art press) volume 39.the Two-phase Xiang Shu of Dachaoshi, 1976.

Tien cheng-yang: ed. Elaboration on the study of celestial being. Beijing: religious culture press, 1999.

Wang Mu: a brief introduction to the Book of enlightenment, Beijing: Zhonghua publishing house, 1990.

Zhang Jiyu: Chinese Taoist collection, vol. 6, Beijing: Huaxia publishing house, 2004.

Can Tong: Collectiona and Notes, volume 9, edited by dong peiwen, Beijing: Religious Culture Press, 2013.

Liu Buxiu: the resources background of the primitive nation choosing the three gorges settlement: salt and cinnabe construct the two pillars for the survival and development of the ancestors, China three gorges construction, no.3, 2003.

Xiao Qin:Cinnabar, the Star of 21st century literature, vol.2011, Beijing: writers publishing house, 2011.

Hu Fuchen: Introduction to the principle of Dan and technique of immortalization. Beijing: Social sciences academic press, 2009. 